\title{
Jurnal
}

\section{NANO-MOSFETS IMPLEMENTATION OF DIFFERENT LOGIC FAMILIES OF TWO INPUTS NAND GATE TRANSISTOR LeVEl CIRCUITS: A SimUlation Study}

\author{
Ooi Chek Yee ${ }^{*}$, Lim Soo King ${ }^{b}$
}

aFaculty of Information and Communication Technology, Universiti Tunku Abdul Rahman, JalanUniversiti, Bandar Barat, 31900 Kampar, Perak, Malaysia

bLee Kong Chian Faculty of Engineering and Science, Universiti Tunku Abdul Rahman, Jalan Sungai Long, Bandar Sungai Long, Cheras, 43000 Kajang, Selangor, Malaysia
Article history

Received

9 November 2016

Received in revised form

28 June 2017

Accepted

10 September 2017

*Corresponding author ooicy@utar.edu.my

\section{Graphical abstract}

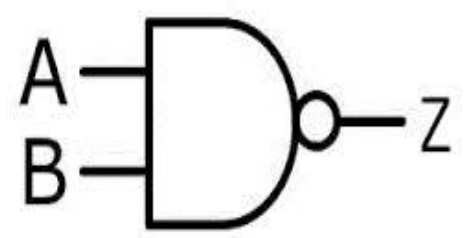

\begin{abstract}
In this paper, simulation study has been carried out on two inputs logic NAND transistor circuits with four different logic families, namely (i) nano-CMOS NAND gate, (ii) nanoMOSFET loaded n-type nano-MOSFET NAND gate, (iii) resistive loaded nano-MOSFET NAND gate, and (iv) pseudo nano-MOSFET NAND gate. The simulation tool used is WinSpice. All the n-type and p-type nano-MOSFETs have channel length (L) $10 \mathrm{~nm}$ with width (W) $125 \mathrm{~nm}$ or $250 \mathrm{~nm}$, depending on type of logic families. The problem with downscaling of nanoMOSFET is the implementation of low power high speed nano-MOSFET transistor circuit. Simulated timing diagrams for input and output waveforms showed correct logical NAND gate operations for all four logic families. Transient analysis on nano-MOSFET loaded n-type nano-MOSFET NAND gate shows that theoretical modeling calculation of rise time (tr), fall time (ff) and maximum operating frequency (fmax) are reasonably matched simulated output result of WinSpice. All the logic family circuits studied shown reduction in dynamic power when MOSFET is downscaled to nanometer regime.
\end{abstract}

Keywords: Logic family, nano-MOSFET, NAND gate, simulation, theory

\begin{abstract}
Abstrak
Penyelidikan simulasi terhadap logic NAND dua talian masukan dengan empat kumpulan logik yang berlainan telah dilaksanakan, iaitu (i) get NAND nano-CMOS, (ii) bebanan nano-MOSFET jenis $n$ get NAND nano-MOSFET, (iii) rintangan get NAND nano-MOSFET, dan (iv) pseudo get NAND nano-MOSFET. Perisian yang digunakan ialah WinSpice. Kesemua nano-MOSFET jenis $n$ dan jenis $p$ yang digunakan mempunyai panjang terusan $(L) 10 \mathrm{~nm}$ dengan lebar (W) $125 \mathrm{~nm}$ atau $250 \mathrm{~nm}$ bergantung kepada jenis kumpulan logik. Masalah pengurangan saiz nano-MOSFET ialah pelaksanaan kuasa rendah dan masa kendalian singkat bagi litar-litar transistor nano-MOSFET. Rajah masa untuk denyutan gelombang masukan dan keluaran menunjukkan kendalian logik NAND yang betul untuk kesemua kumpulan logik. Analisis terhadap bebanan nano-MOSFET jenis n get NAND menunjukkan masa bangkit, masa jatuh dan kalaan operasi maksima adalah lebih kurang sama dari segi teori dan simulasi. Kesemua kumpulan logic memaparkan pengurangan kuasa dinamik bila saiz MOSFET dikurangkan kelinkungan nanometer.
\end{abstract}

Kata kunci: Kumpulan logik, nano-MOSFET, get NAND, simulasi, teori

(C) 2017 Penerbit UTM Press. All rights reserved 


\subsection{INTRODUCTION}

Downscaling of MOSFET structural dimensions from micrometer regime to nanometer regime have occurred over the last few decades [1-6]. The conventional bulk CMOS technology is rapidly continuously downscaling until approaching the scaling limits. The MOSFET channel length $L$ is approaching $10 \mathrm{~nm}$. In order to enable gate to control charge in the channel, the requirement Tox $<<$ $L$ must be met, where Tox is the oxide insulator thickness $[7,8]$. In this study, the gate oxide thickness is approaching $1.5 \mathrm{~nm}$, that is the oxide insulator is few atoms thick. Meanwhile, the nano-MOSFET width W used in this study is $125 \mathrm{~nm}$ or $250 \mathrm{~nm}$ depending on the type of logic families [9-11]. In this study, NAND logical functions are implemented using four different logic families, namely: (i) nano-CMOS NAND gate, (ii) nano-MOSFET loaded n-type nano-MOSFET NAND gate, (iii) resistive loaded $(748.8 \Omega)$ nano-MOSFET NAND gate, and (iv) pseudo nano-MOSFET NAND gate. Timing requirements for these NAND gates are analyzed using WinSpice [12-14]. WinSpice output show correct logical NAND operation. Transient analysis on timing requirements are carried out on nano-MOSFET loaded n-type nano-MOSFET NAND circuit to compare theoretical modeling calculation results and simulation output results $[15,16]$. The low power high speed characteristic of NAND designed using $10 \mathrm{~nm}$ nano-MOSFET logic circuit are benchmarked with NAND designed using $45 \mathrm{~nm}$ MOSFET $[1,10]$. The simulation result in this project showed these characteristics.

\subsection{METHODOLOGY}

Device simulation is carried out by using on-line simulator NanoMOS developed by Purdue University. Then, the CIR Spice code files for four different logic families 2 inputs NAND circuit are simulated using Winspice. The input timing diagrams and output timing diagrams are the output result of WinSpice simulation. To test the 2 inputs NAND circuits logical operation, two input signals with period 20 ns and 30 ns are used. Meanwhile, to analyze transient response (rise time, fall time and maximum operating frequency), two input signals with 20 ps and 30 ps are used.

\subsection{Theory}

By using on-line device simulator NanomOS, the nano-MOSFET device parameters (refer to Table 1) and current-voltage (I-V) graphs (refer to Figure 1 and Figure 2) are obtained, which are used to calculate the timing response for nano-MOSFET loaded nano-MOSFET NAND circuit (refer to Table 2).
Table 1 Structural Dimension of nano-MOSFET

\begin{tabular}{ll}
\hline \multicolumn{2}{l}{ Double Gate nano-MOSFET Device Simulation Parameters } \\
\hline Vgs & $0.60 \mathrm{~V}$ \\
Vds & $0.60 \mathrm{~V}$ \\
$V_{\text {TO }}$ & $0.20 \mathrm{~V}$ \\
Source/Drain Doping Concentration (ND) & $1 \times 10^{20} \mathrm{~cm}^{-3}$ \\
Channel Body Acceptor Impurity & \\
Concentration (NA) & $1 \times 10^{16} \mathrm{~cm}^{-3}$ \\
Channel Width (W) & $125 \mathrm{~nm}$ \\
Channel Length (L) & $10 \mathrm{~nm}$ \\
Source Length/Drain Length (LsD) & $7.5 \mathrm{~nm}$ \\
Silicon Channel Thickness (TSi) & $1.5 \mathrm{~nm}$ \\
Top/Bottom Oxide Insulator Thickness (Tox) & $1.5 \mathrm{~nm}$ \\
Top/Bottom Insulator Relative Dielectric & 3.9 \\
Constant & 11.7 \\
Channel Body Relative Dielectric Constant \\
Top/Bottom Gate Contact Work Function \\
\hline
\end{tabular}

Table 2 Theoretical Modeling Calculation Values of nano MOSFET Loaded nano-MOSFET NAND Circuit

\begin{tabular}{ll}
\hline \multicolumn{2}{l}{ Double Gatenano-MOSFET Loaded NAND Gate } \\
\hline Gate Capacitance (Cg) & $5.7551 \times 10^{-17} \mathrm{~F}$ \\
Area Capacitance (Ca) & $1.6125 \times 10^{-19} \mathrm{~F}$ \\
Sidewall Capacitance (CsW) & $6.072 \times 10^{-17} \mathrm{~F}$ \\
Total Drain Capacitance (Cd) & $4.6041 \times 10^{-18} \mathrm{~F}$ \\
Total Source Capacitance (Cs) & $1.0469 \times 10^{-17} \mathrm{~F}$ \\
nano-MOSFET Loaded Resistance (Rload) & $748.8 \Omega$ \\
nano-MOSFET on-state Resistance (Ron) & $36.2 \Omega$ \\
Loaded NAND Gate Total Capacitance & $1.3351 \times 10^{-16} \mathrm{~F}$ \\
at Output Node (Ctotal) & \\
Total Capacitance between & Two \\
nano-MOSFETs Connection (Csd) & $1.5073 \times 10^{-17} \mathrm{~F}$ \\
Rise Time Constant (tr) & $9.99688 \times 10^{-14} \mathrm{~S}$ \\
Rise Time (tr) & $1.34158 \times 10^{-12} \mathrm{~S}$ \\
Fall Time Constant ( $\mathrm{ff}$ ) & $1.02114 \times 10^{-14} \mathrm{~S}$ \\
Fall Time (tf) & $2.24652 \times 10^{-14} \mathrm{~S}$ \\
Propagation Delay (tp) & $3.81856 \times 10^{-14} \mathrm{~S}$ \\
Maximum Signal Frequency (fmax) & $7.33113 \times 10^{11} \mathrm{~Hz}$ \\
\hline
\end{tabular}




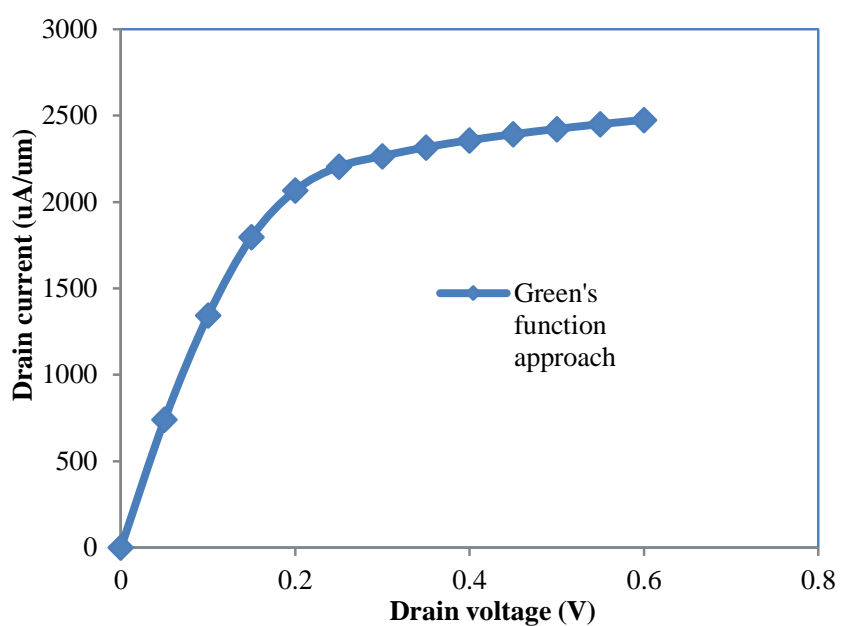

Figure 1 Drain Current- Drain Voltage Curve of nano-MOSFET

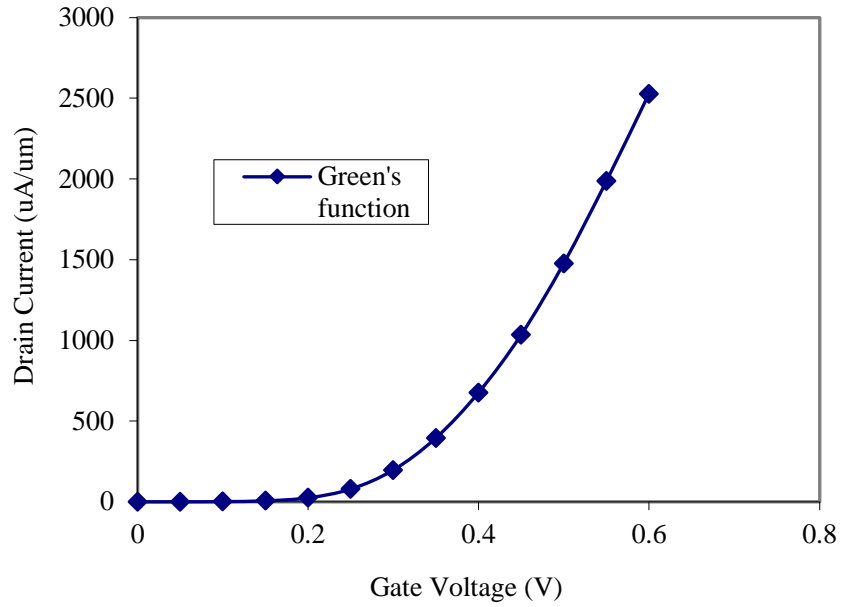

Figure 2 Drain Current- Gate Voltage Curve of nano-MOSFET

Equations and theories which are used to obtain data in Table 2 are listed below:

$R_{\text {Load }}=\left(\frac{V_{D S}}{I_{D S}}\right)=\frac{V_{\text {th }}}{I_{\text {on-stat eat linear region }} \times W}$

since digital logic gates operate at linear portion of $\mathrm{I}$ V curve

$\mathrm{R}_{\text {channel at on-state }}=\frac{1}{\mu_{\mathrm{n}} \mathrm{C}_{\mathrm{Ox}}\left(\frac{\mathrm{W}}{\mathrm{L}}\right)\left(\mathrm{V}_{\mathrm{DD}}-\mathrm{V}_{\mathrm{th}}\right)}$

$\mu_{\mathrm{n}}=$ electron mobility at ballistic $=1200 \mathrm{~cm}^{2} / \mathrm{Vs}$

$\mathrm{C}_{\mathrm{Ox}}=$ Oxide capacitance per unit area

Rise time constant $(\tau r)=$ RLoad $\times$ NAND gate total capacitance
Rise time $(\mathrm{tr})=2.2 \times \operatorname{\tau r} \times 6.1$, it takes 6.1 times duration to pass logic 1 than logic 0 through an $n$-channel MOS pass-transistor

Fall time constant $(\tau f)=($ Ctotal $\times 2$ Rchannel on-state $)+$ (Csd $x$ Rchannel on-state), Elmore formula has been used since two nano-MOSFETs are connected in series

Fall time $(\mathrm{tf})=2.2 \times \tau f$

Propagation delay $(t p)=0.35(\tau r+\tau f)$

Maximum signal frequency $(\mathrm{fmax})=1 /(\mathrm{tr}+\mathrm{tf})$

The equation used to obtain dynamic power is:

$P(d y n)=a C f V_{D D^{2}}$

Where $a$ is the activity coefficient, $C$ is the capacitance at output node, $f$ is the frequency of switching and $V_{D D}$ is the voltage supply [17-19].

\subsection{RESULTS AND DISCUSSION}

Modern MOSFET devices operate between the driftdiffusion and ballistic regimes. So, quasi-ballistic transport is examined in this paper.

Figure 3, Figure 4, Figure 5 and Figure 6 show the schematic circuits of all four logic families NAND gate.

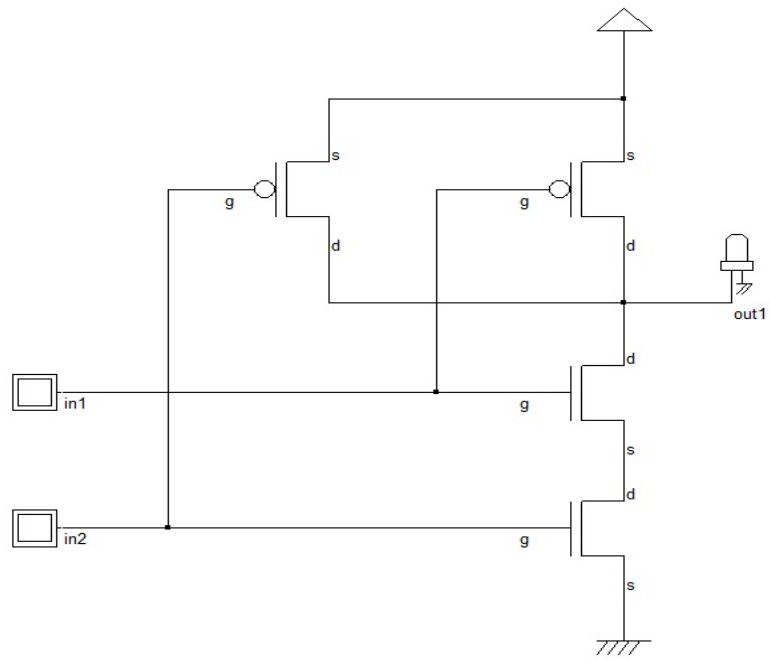

Figure 3 Two inputs nano-CMOS NAND circuit

Their timing diagrams are shown in Figure $7(a)$, $7(b)$ and $7(c)$, Figure $8(a), 8(b)$ and $8(c)$, Figure $9(a)$, $9(\mathrm{~b})$ and $9(\mathrm{c})$, as well as Figure 10(a), 10(b) and 10 (c), accordingly. The first input signal to all four logic families has a period of 20 ns (with $50 \%$ duty cycle).The second input signal to all four logic families has a period of 30 ns (with $50 \%$ duty cycle). 


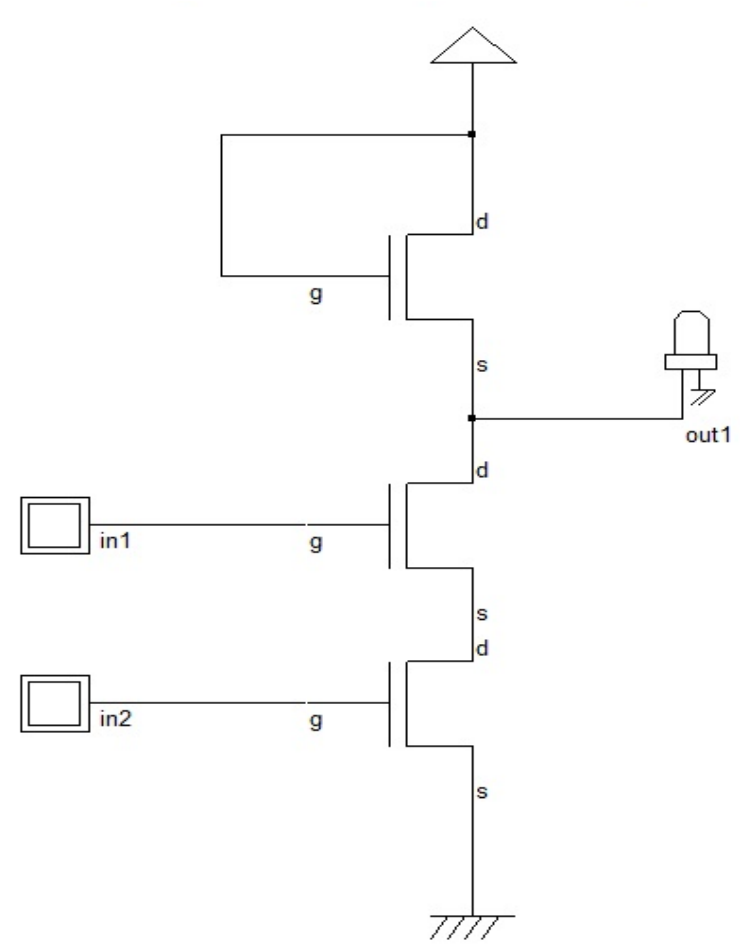

Figure 4 Two inputs nano-MOSFET loaded nano-MOSFET NAND circuit

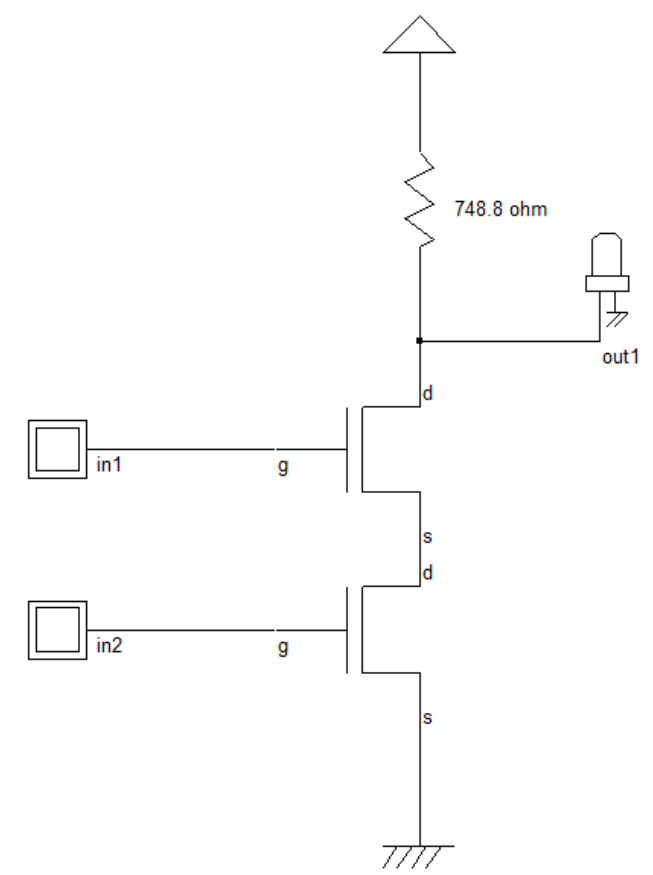

Figure 5 Two inputs resistive loaded nano-MOSFET NAND circuit

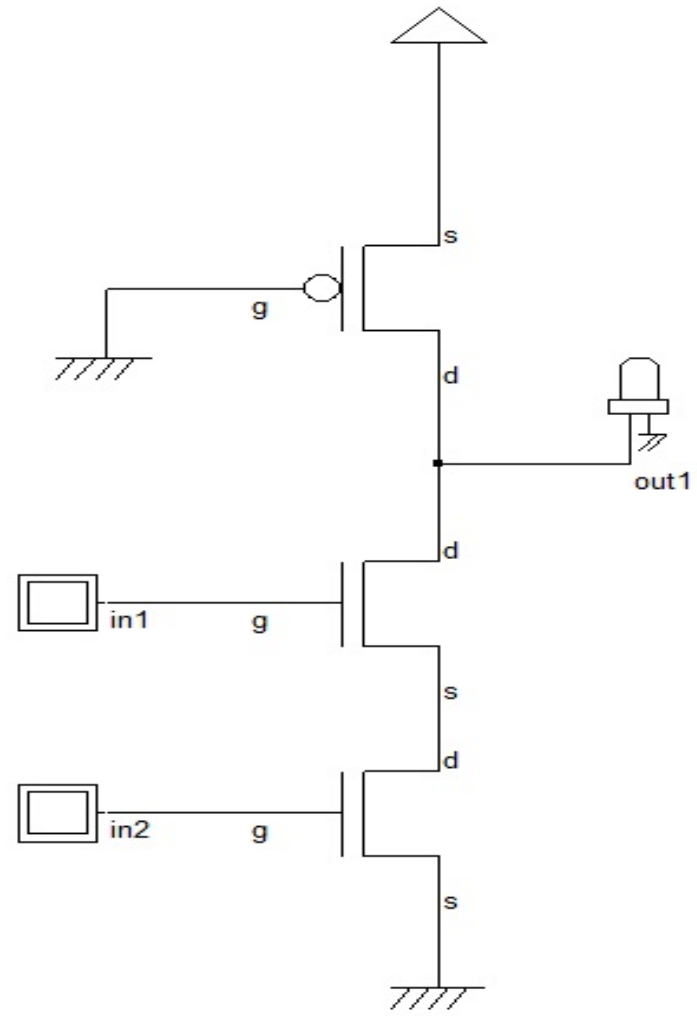

Figure 6 Two inputs pseudo nano-MOSFET NAND circuit

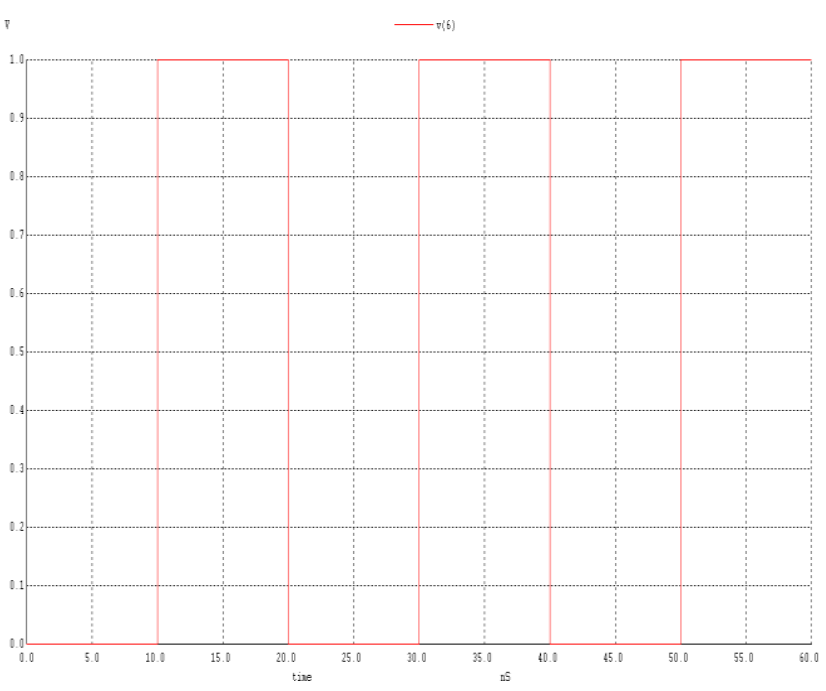

Figure 7(a) First input signal to nano-CMOS NAND circuit 


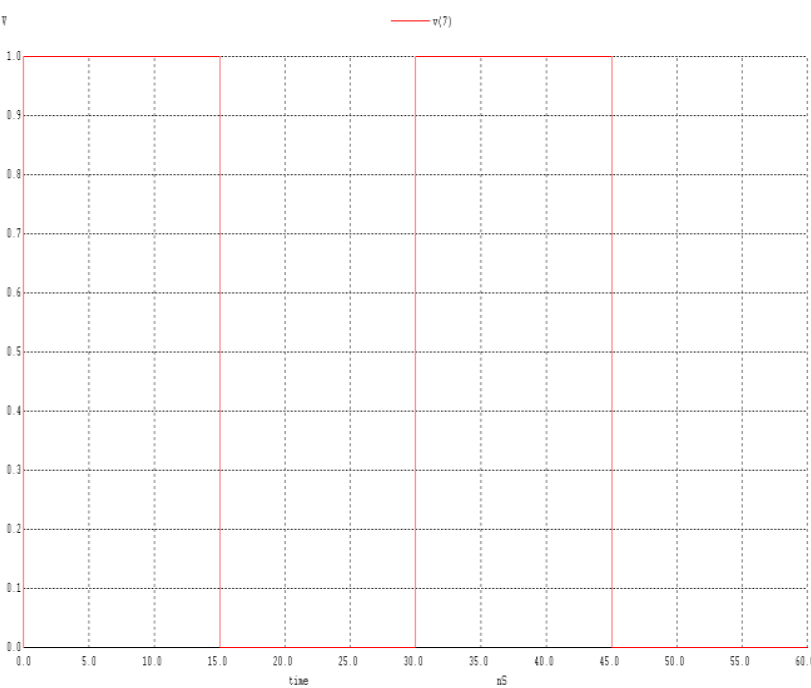

Figure 7(b) Second input signal to nano-CMOS NAND circuit

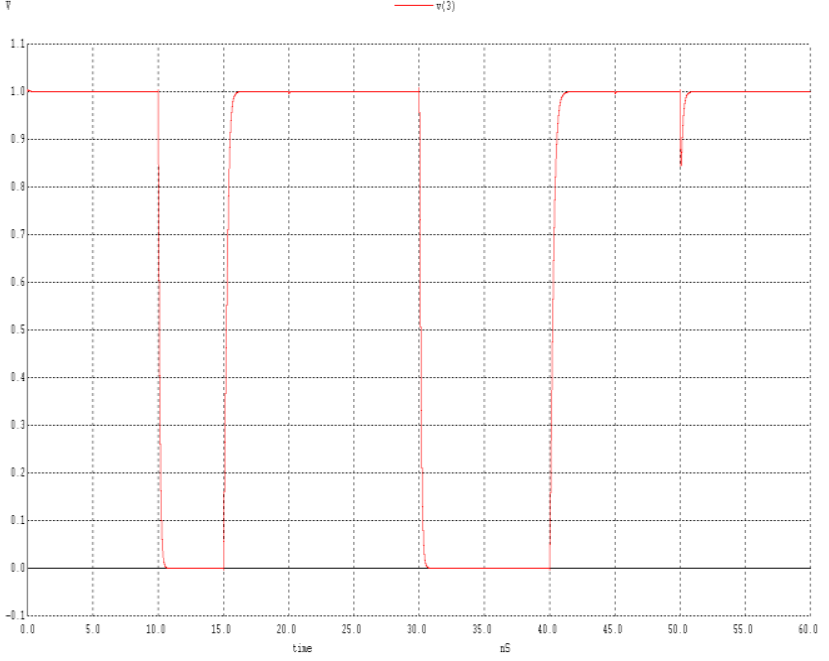

Figure 7(c) Output signal of nano-CMOS NAND circuit

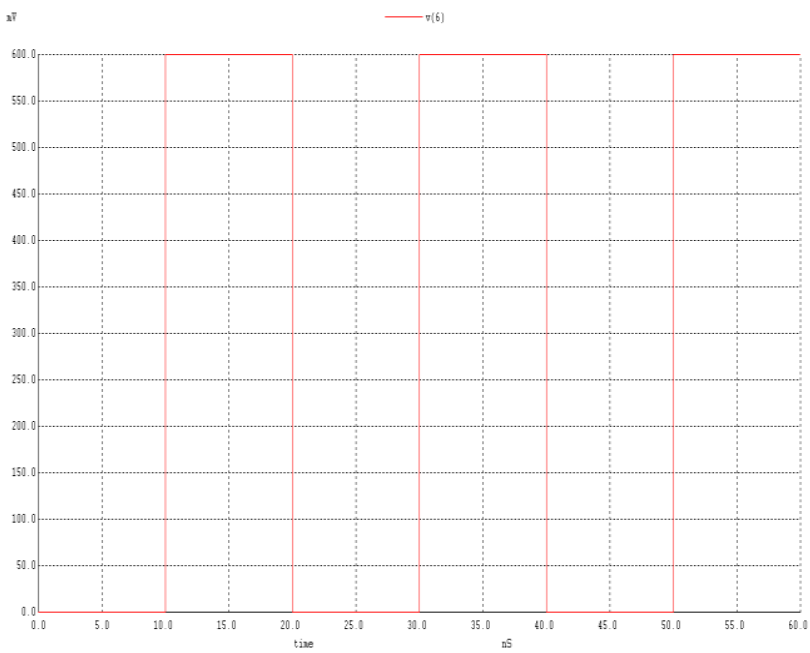

Figure 8(a) First input to nano-MOSFET loaded nano-MOSFET NAND circuit

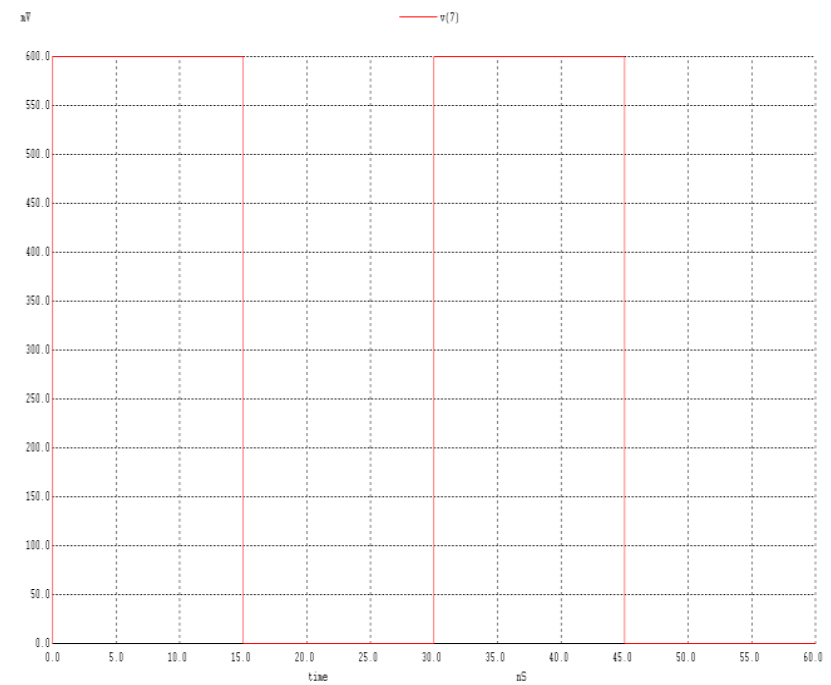

Figure 8(b) Second input to nano-MOSFET loaded nanoMOSFET NAND circuit

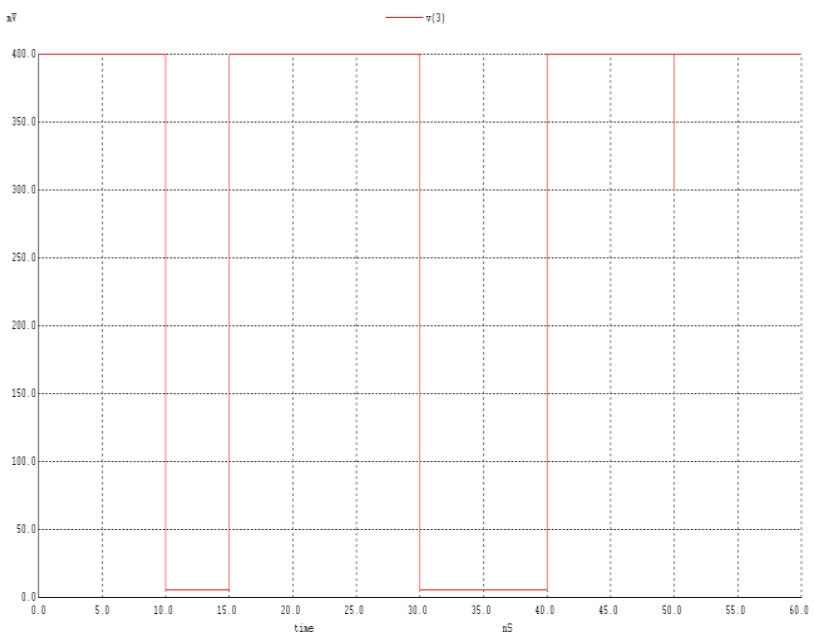

Figure $\mathbf{8}(\mathbf{c})$ Output of nano-MOSFET loaded nano-MOSFET NAND circuit

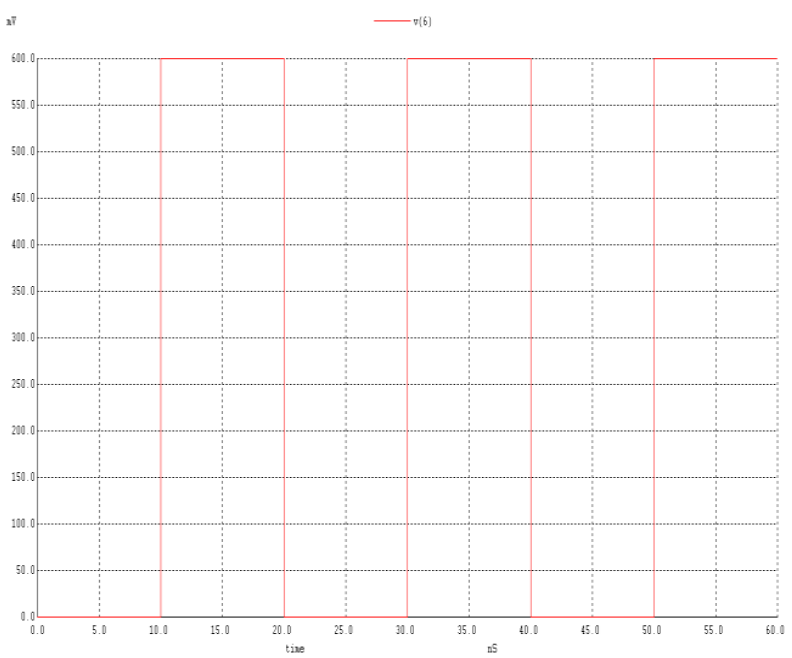

Figure $\mathbf{9 ( a )}$ First input to resistive loaded nano-MOSFET NAND circuit 


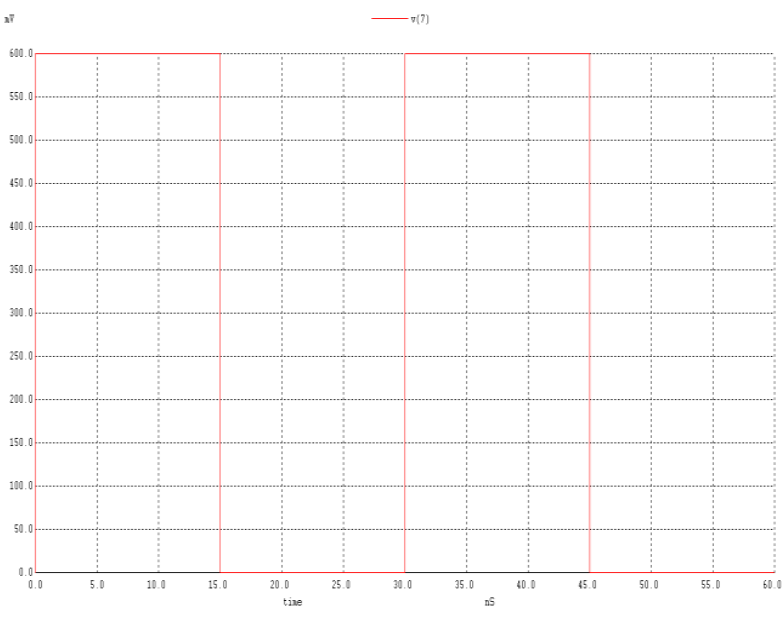

Figure $\mathbf{9}(\mathbf{b})$ Second input to resistive loaded nano-MOSFET NAND circuit

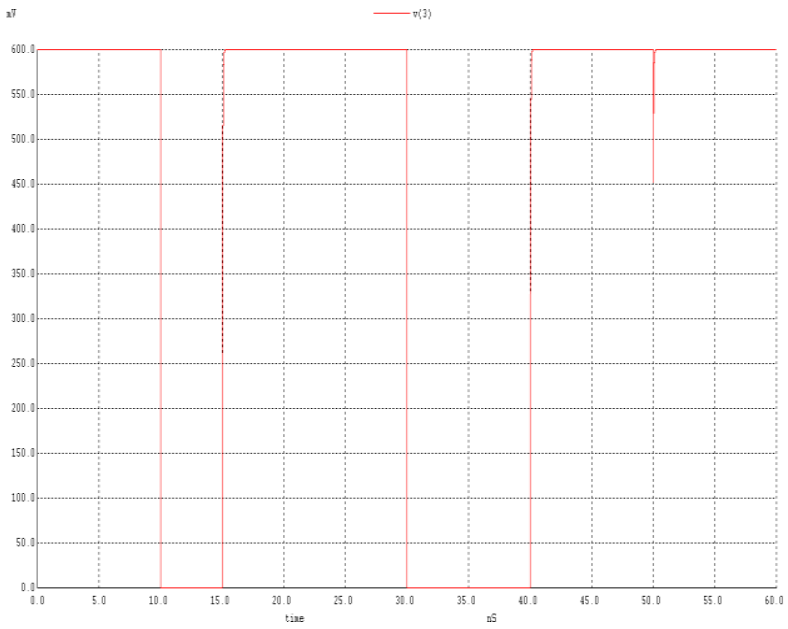

Figure $\mathbf{9 ( c )}$ Output of resistive loaded nano-MOSFET NAND circuit

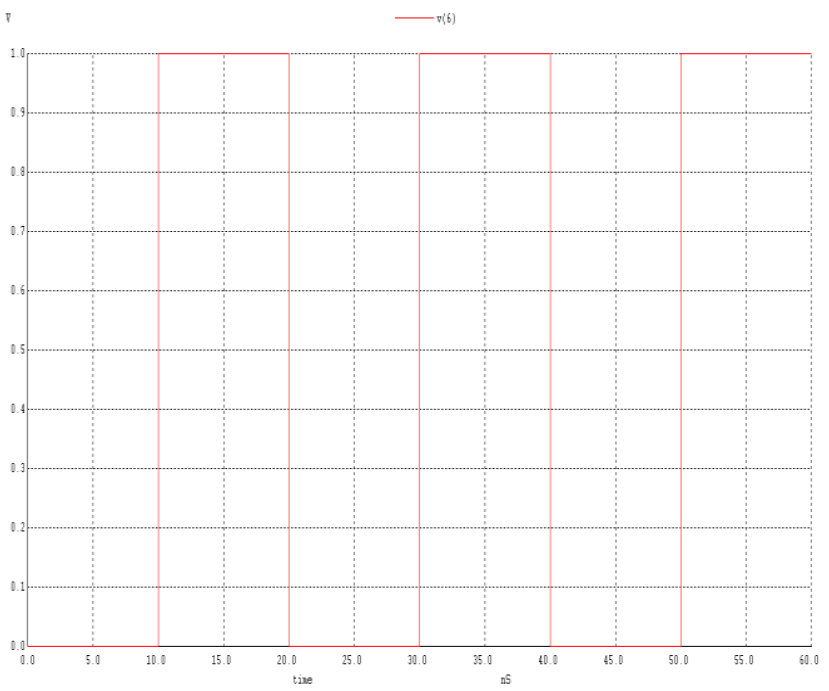

Figure 10(a) First input to pseudo nano-MOSFET NAND circuit

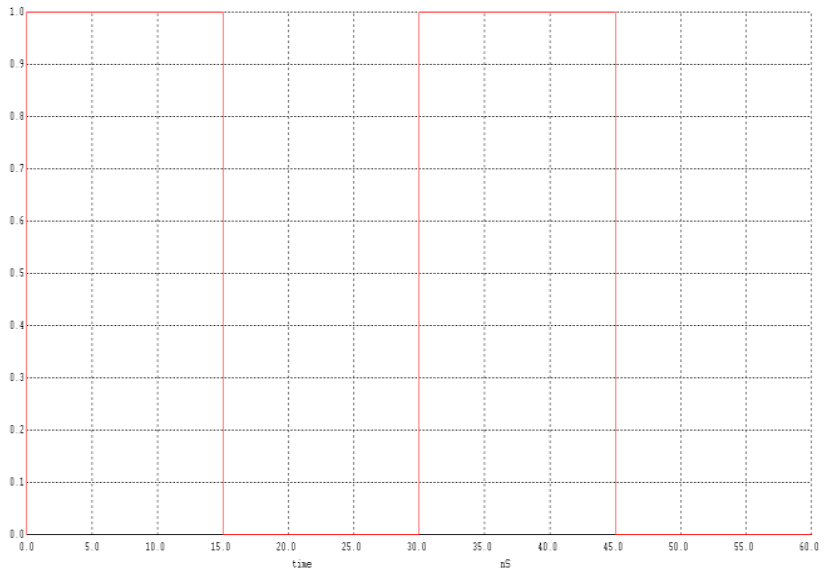

Figure $\mathbf{1 0 ( b )}$ Second input to pseudo nano-MOSFET NAND circuit

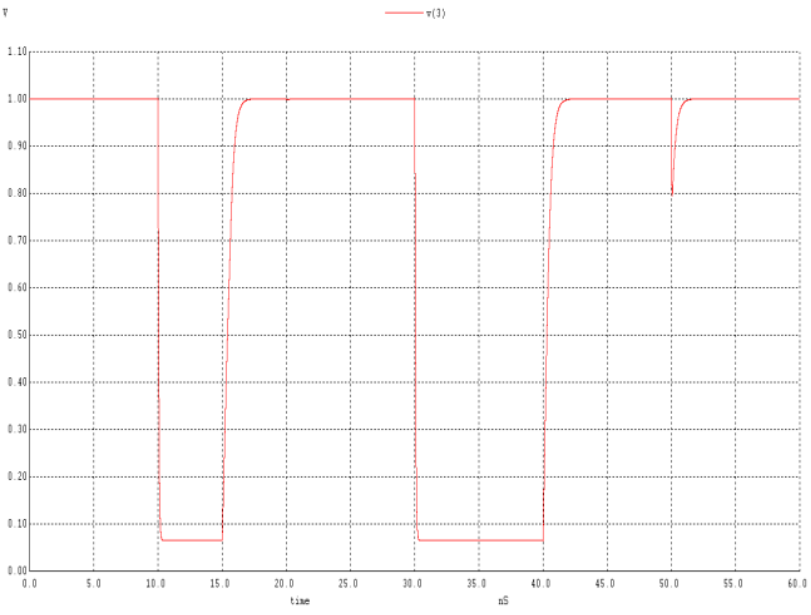

Figure 10 (c) Output of pseudo nano-MOSFET NAND circuit

The above input and output signal timing diagrams show correct logical NAND operation for all four logic families. The output signal of nano-MOSFET loaded NAND circuit shows a threshold voltage loss of $0.2 \mathrm{~V}$ since the nano-MOSFET load acts as a pass transistor which passes a weak logic level 1 and passes a strong logic level 0 . The threshold voltage loss $0.2 \mathrm{~V}$ corresponds to the threshold voltage of nanoMOSFET which is $0.2 \vee[20,21]$. The nano-MOSFET pass transistor load is equivalent to $748.8 \Omega$ load resistance. This $748.8 \Omega$ resistance is calculated from the nanoMOSFET current-voltage (I-V) curve in the linear portion where digital operation occurred as shown in Figure 1. By this way, resistive loaded $748.8 \Omega$ nanoMOSFET NAND circuit is formed as shown in Figure 5.

Figure $11(a), 11(b)$ and $11(c)$ show transient analysis timing diagrams for nano-MOSFET loaded NAND circuit. 


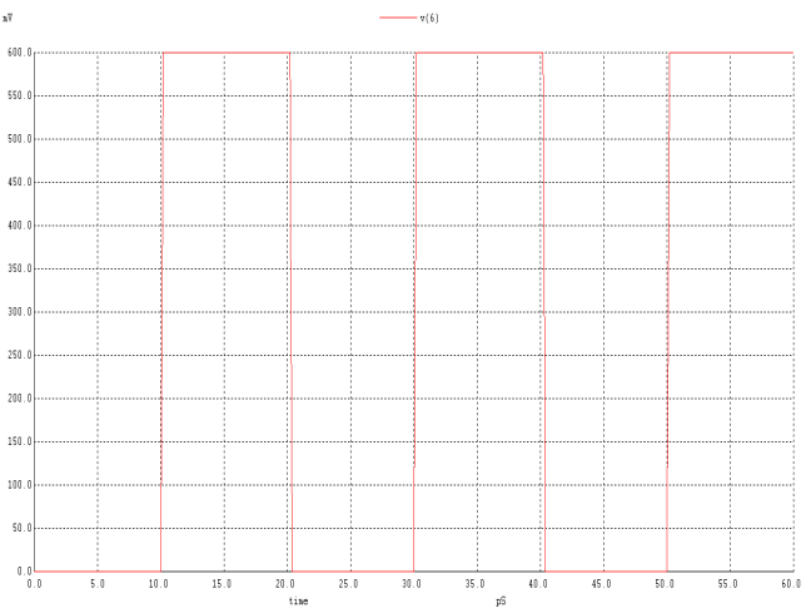

Figure 11(a) First input to nano-MOSFET loaded nanoMOSFET NAND circuit for transient analysis

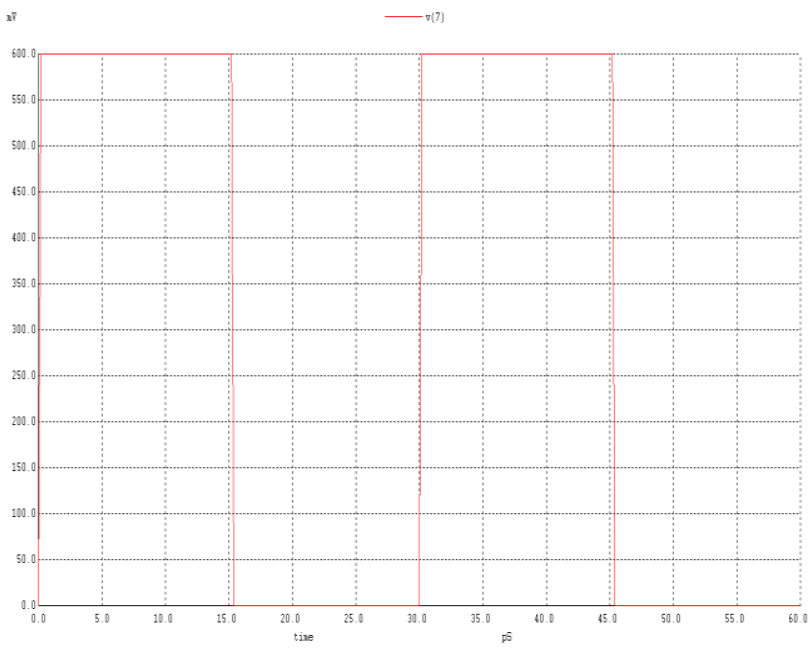

Figure 11(b) Second input to nano-MOSFET loaded nanoMOSFET NAND circuit for transient analysis

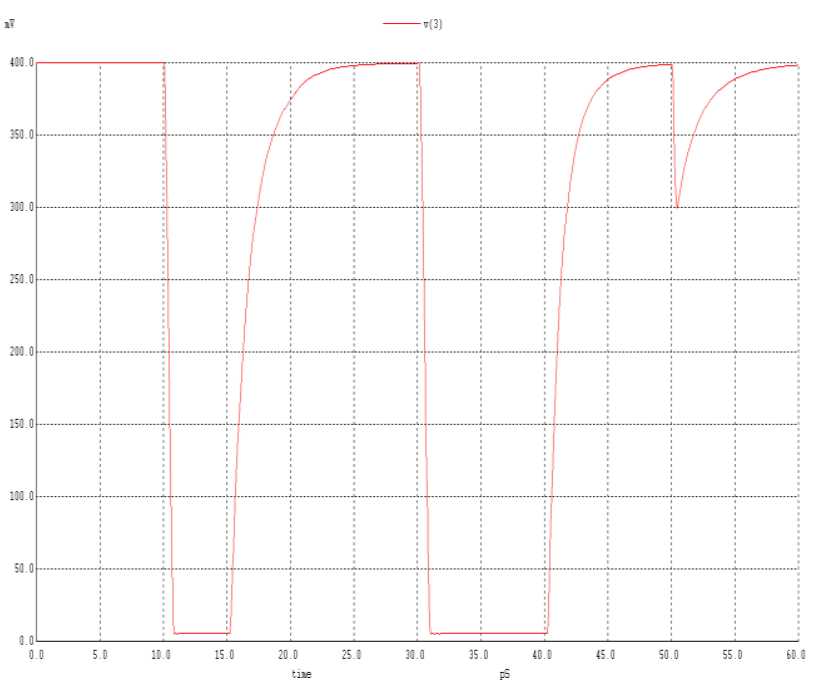

Figure 11(c) Output of nano-MOSFET loaded nano-MOSFET NAND circuit for transient analysis
The period of the 2 input signals to this NAND circuit is 20 ps and 30 ps. Rise time and fall time are taken between $10 \%$ and $90 \%$ of output voltage signal at rising edge and falling edge, respectively. Rise time is due to charging circuit whereas fall time is due to discharging circuit. Table $3(a)$ and $3(b)$ show the rise time, fall time and maximum operating frequency of this transient analysis by theoretical modeling calculations and from Winspice simulation output. From [1], the DG MOSFET NOT propagation delay is $16 \mathrm{ps}$ and from [10], the propagation delay for $45 \mathrm{~nm}$ MOSFET 2 input NAND is 8.719 ps. When compared with theoretical and simulated propagation delay, which are $3.818 \times 10^{-14} \mathrm{~s}$ and $1.79 \times 10^{-13} \mathrm{~s}$, respectively, of 2 input NAND designed with $10 \mathrm{~nm}$ nano-MOSFET has a faster speed. Therefore, downscaling nanoMOSFET has lead to faster speed of logic circuits [9].

Table 3(a) Theoretical Calculation Value for NAND nanotransistor Loaded Circuit

Theoretical Modeling Calculations from NanoMOS Device Simulation Data ( $10 \%$ and $90 \%$ Points)

\begin{tabular}{lllll}
$\begin{array}{l}\text { Logic } \\
\text { Gates }\end{array}$ & Rise Time (tr) & Fall Time (tf) & $\begin{array}{l}\text { Propagation } \\
\text { Delay (tp) }\end{array}$ & $\begin{array}{l}\text { Maximum } \\
\text { Operating } \\
\text { Frequency } \\
\text { (fmax) }\end{array}$ \\
\hline NAND & $1.341 \times 10^{-12} \mathrm{~s}$ & $2.246 \times 10^{-14} \mathrm{~s}$ & $3.818 \times 10^{-14} \mathrm{~s}$ & $7.331 \times 10^{11} \mathrm{~Hz}$ \\
\hline
\end{tabular}

Table 3(b) WinSpice Simulation Value for NAND nanotransistor Loaded Circuit

\section{WinSpice Simulation Results Using} Model Level MOS6 ( $10 \%$ and $90 \%$ Points)

\begin{tabular}{lllll}
$\begin{array}{l}\text { Logic } \\
\text { Gates }\end{array}$ & Rise Time (tr) & Fall Time (tf) & $\begin{array}{l}\text { Propagation } \\
\text { Delay (tp) }\end{array}$ & $\begin{array}{l}\text { Maximum } \\
\text { Operating } \\
\text { Frequency } \\
\text { (fmax) }\end{array}$ \\
\hline NAND & $2.727 \times 10^{-12} \mathrm{~s}$ & $68.18 \times 10^{-14} \mathrm{~s}$ & $1.79 \times 10^{-13} \mathrm{~S}$ & $2.933 \times 10^{11} \mathrm{~Hz}$ \\
\hline
\end{tabular}

In nano-CMOS NAND circuit, n-type nano-MOSFET has $W=125 \mathrm{~nm}$ each and $p$-type nano-MOSFET has $\mathrm{W}=250 \mathrm{~nm}$ each to counter-balance the difference in electron and hole mobility. In nano-MOSFET loaded NAND circuit, the n-type nano-MOSFET load has $\mathrm{W}=$ $125 \mathrm{~nm}$ and the bottom n-type nano-MOSFETs has $\mathrm{W}=250 \mathrm{~nm}$ each. This condition is need to meet

$$
\left(\frac{W}{L}\right)_{n} \geq 2\left(\frac{W}{L}\right)_{\text {Load }}
$$

in order to reduce output low voltage $\mathrm{V}_{\mathrm{ol}}$. In pseudo nano-MOSFET NAND circuit, p-type nano-MOSFET has $\mathrm{W}=125 \mathrm{~nm}$ and $\mathrm{n}$-type nano-MOSFET has $\mathrm{W}=250 \mathrm{~nm}$. This condition is needed to meet the same criteria in above expression in order to reduce Vol. Meanwhile, 
in resistive loaded $748.8 \Omega$ nano-MOSFET NAND circuit, $748.8 \Omega$ resistance is the load and n-type nano-MOSFET has $\mathrm{W}=250 \mathrm{~nm}$ [22].. In nano-MOSFET loaded NAND circuit, VoL is theoretically calculated using

$$
V_{O L}=\frac{2 \times R_{\text {on }}}{\left(2 \times R_{\text {on }}\right)+R_{\text {load }}} \times V_{D D}
$$

This theoretical value is $52.90 \mathrm{mV}$. When compared with WinSpice simulated value $9 \mathrm{mV}$, the ratio is 5.87 . From theoretical modeling and also WinSpice simulation, output high voltage $\mathrm{V}_{\mathrm{OH}}$ is $0.4 \mathrm{~V}$. When at least one out of two nano-MOSFETs at the bottom of the circuit is at off state, and thereby at high impedance state, threshold voltage loss $0.2 \mathrm{~V}$ occurs at the top side nano-MOSFET load. Therefore, $\mathrm{V}_{\mathrm{OH}}$ is $0.4 \mathrm{~V}$.

To investigate the dynamic power during downscaling of nano-MOSFET, refer to Table 4.

Table 4 Dynamic Power for Four Different NAND Logic

\begin{tabular}{|c|c|c|c|c|}
\hline & $\begin{array}{l}\text { nano- } \\
\text { CMOS } \\
\text { NAND }\end{array}$ & $\begin{array}{l}\text { nano- } \\
\text { MOSFET } \\
\text { loaded } \\
\text { NAND }\end{array}$ & $\begin{array}{l}\text { Pseudo } \\
\text { nano- } \\
\text { MOSFET } \\
\text { NAND }\end{array}$ & $\begin{array}{l}\text { Resistive } \\
\text { loaded } \\
\text { NAND }\end{array}$ \\
\hline $\begin{array}{l}\text { Dynamic } \\
\text { Power } \\
\text { (Watts) }\end{array}$ & $1.29 \times 10^{-10}$ & $4.50 \times 10^{-10}$ & $8.63 \times 10^{-11}$ & $1.55 \times 10^{-11}$ \\
\hline $\begin{array}{l}\text { Voltage } \\
\text { Supply } \\
\text { (Volts) } \\
\text { Frequency } \\
\text { of } \\
\text { switching } \\
\text { (Hertz) }\end{array}$ & $5 \times 10^{7}$ & $5 \times 10^{7}$ & $5 \times 10^{7}$ & $5 \times 10^{7}$ \\
\hline
\end{tabular}

The equation used to obtain dynamic power is:

$P(d y n)=a C f V_{D D^{2}}$

Where $a$ is the activity coefficient, $c$ is the capacitance at output node, $f$ is the frequency of switching and $V_{D D}$ is the voltage supply. For two input NAND logic $a=0.1875$. Normally, in conventional bulk micrometer MOSFET logic, dynamic power is about $\mu \mathrm{W}$. So, from Table 4, reduction in dynamic power is observed during down scaling. From [1], the power dissipation of DG MOSFET NOT is $10 \mu \mathrm{W}$ and from [10], the power dissipation of 2 inputs NAND with $45 \mathrm{~nm}$ nano-MOSFET is $18.32 \mathrm{nW}$. When compared with power in Table 4, it is obvious that downscaling of nano-MOSFET has lead to reduction of dynamic power of NAND circuit implemented using $10 \mathrm{~nm}$ nano-MOSFET. Therefore, low power logic circuits are achieved when designed using $10 \mathrm{~nm}$ nano-MOSFET $[2,16]$.

\subsection{CONCLUSION}

Logical two inputs NAND circuit operation can be implemented by using nano-MOSFETs with four different logic families. Conventional bulk MOSFETs can be replaced by nano-MOSFETs to implement NAND transistor level circuits. In this paper, this development in semiconductor industry has been shown by simulation study using WinSpice and observing input timing diagrams and output timing diagrams. Correct logical NAND operations are observed from these simulation output. During downscaling of MOSFET to nanometer regime, dynamic power of logic NAND circuit is reduced. Low power high speed 2 input NAND logic has been achieved in this simuation project.

\section{References}

[1] Reza Hosseini and Neda Teimuorzadeh. 2013. Simulation Study of Circuit Performance of GAA Silicon Nanowire Transistor and DG MOSFET. Physical Review \& Research International. 3(4): 568-576.

[2] P. A. Gowri Sankar and K. Udhaya kumar. 2014. MOSFETlike CNFET Based Logic Gate Library for Low-power Application: A Comparative Study. Journal of Semiconductors. 35(7).

[3] Ulrich Wulf, Marcus Krahlisch and Hans Richter. 2011. Scaling Properties of Ballistic Nano-transistors. Nanoscale Research Letters. 6: 365.

[4] Manorama, Pavan Shrivastava and Shyam Akashe. 2012 Design and Analysis of Leakage Current and Delay for Double-Gate MOSFET at $45 \mathrm{~nm}$ in CMOS Technology. IEEE. 978-1-4673-4603-0.

[5] A. Abdolahzadeh Ziabari, M. Charmi and H. R. Mashayekhi. 2013. The Impact of Body Doping Concentration on the Performance of Nano DG-MOSFETs: A Quantum Simulation. Chinese Journal of Physics. 51 (4): 844-853.

[6] Changwook Jeong, Dimitri Antoniadis and Mark S. Lundstrom. 2009. On Backscattering and Mobility in Nanoscale Silicon MOSFETs. IEEE Transactions on Electron Devices. 56(11): 2762-2769.

[7] Marc Baldo. 2011. Introduction to Nanoelectronics. MIT Open Course Ware Publication.

[8] George W. Hanson. 2008. Fundamentals of nanoelectronics. Pearson International Edition.

[9] K. Navi, M. Rashtian, A. Khatir, P. Keshavarzian and $O$. Hashemipour. 2010. High Speed Capacitor-inverter Based Carbon Nanotube FullAdder. Nanoscale Research Letters. 5: 859-86.

[10] Michael Loong Peng Tan, Georgios Lentaris and Gehan AJ Amaratunga. 2012. Device and Circuit-level Performance of Carbon Nanotube Field-Effect Transistor with Benchmarking against A Nano-MOSFET. Nanoscale Research Letters. 7: 467.

[11] Huei Chaeng Chin, Cheng Siong Lim, Weng Soon Wong and Michael Loong Peng Tan. 2014. Enhanced Device and Circuit-level Performance Benchmarking of Graphene Nanoribbon Field-Effect Transistor against A Nano-MOSFET with Interconnects. Journal of Nanomaterials. 2014. Article ID 879813.

[12] Rohini Gupta, Bogdan Tutuianu and Lawrence T. Pileggi. 1997. The Elmore Delay as a Bound for RC Trees with Generalized Input Signals. IEEE Transactions on ComputerAided Design of Integrated Circuits and Systems. 16(1): 95104.

[13] Yiming Li and Chih-Hong Hwang, 2008. High-frequency 
Characteristic Fluctuations of Nano-MOSFET Circuit Induced by Random Dopants, IEEE Transactions on Microwave Theory and Techniques. 56(12): 2726-2733.

[14] Ming-Hung Han, Yiming Li and Chih-Hong Hwang. 2010. The Impact of High-frequency Characteristics Induced by Intrinsic Parameter Fluctuations in Nano-MOSFET Device and Circuit. Microelectronics Reliability. 50: 657-661.

[15] A. A. A. Nasser, Moustafa H. Aly, Roshdy A. Abdel Rassoul, Ahmed Khourshed. 2011. Performance of Near-ballistic Limit Carbon Nano-Transistor (CNT) Circuits. ICCTA. 175182.

[16] Hesham F. A. Hamed, Savas Kaya and Janusz A. Starzyk. 2008. Use of Nano-scale Double-Gate MOSFETs in Lowpower Tunable Current Mode Analog Circuits. Analog IntegrCirc Sig Process. doi10.1007/s10470-008-9134-4.

[17] ZhibinRen. 2001. Nanoscale MOSFETs: Physics, Simulation and Design. Purdue University.

[18] Mark Lundstrom. 2005. Notes on the Ballistic MOSFET.
Network for Computational Nanotechnology. Purdue University.

[19] Raseong Kim and Mark Lundstrom. 2011. Notes on FermiDirac Integrals. Network for Computational Nanotechnology. Purdue University.

[20] Ooi Chek Yee and Lim Soo King. 2015. Simulation Study on the Electrical Performance of Equilibrium Thin-body Double-Gate Nano-MOSFET. Jurnal Teknologi. 76: 87-95.

[21] Ooi Chek Yee and Lim Soo King. 2016. Simulation Study of 2D Electron Density in Primed and Unprimed Subband Thin-body Double-Gate Nano-MOSFET of Three Different Thicknesses and Two Temperature States. International Journal of Nanoelectronics and Materials. 9: 67-84.

[22] Sanjeet Kumar Sinha and Saurabh Chaudhury. 2012. Simulation and Analysis of Quantum Capacitance in Single-Gate MOSFET, Double-Gate MOSFET and CNTFET Devices for Nanometer Regime. IEEE 978-1-4673-4700-6. 